\title{
MANUEL TOUSSAINT, ACADEMICO DE LA HISTORIA
}

$\mathbf{P} O \mathbf{R}$

\section{MANUEL ROMERO DE TERREROS}

G ALLABASE Toussaint todavía en sus años mozos cuando empezó a 1 dirigir su mirada a las cosas de arte en nuestro suelo, y desde entonces no ha descansado su pluma en evocar figuras y describir monumentos del pasado que, si se me permite la frase, ha redescubierto, ya que muchas de aquéllas yacían olvidadas y no pocos de éstos eran completamente desconocidos. Así, ha trazado de manera erudita a la par que amena la historia de la Arquitectura Religiosa en la Nueva España Durante el Siglo XVI, en el sexto tomo de la serie Iglesias de México, y una excelente disertación sobre la Pintura en México durante la misma centuria, en un cuaderno de la Enciclopedia Ilustrada. Si en la primera describe con mano maestra viejas iglesias, conventos y catedrales, no menos galanamente nos habla en la segunda de los admirables frescos que a tales edificios exornaban y de las primeras figuras que ejercieron el arte de Apeles en nuestro suelo.

Todos seguramente habréis leído con deleite sus Paseos Coloniales, libro lleno de atinados conceptos y de hábiles y exactas descripciones, con el que nos lleva de la mano a diversos sitios de la República y nos hace conocer y admirar los monumentos de la época virreinal que allí se encuentran; así como sus dos excelentes monografías de las viejas ciudades Tasco y Pátzcuaro, que difícilmente podrán ser superadas, ambas obras acompañadas de magníficas ilustraciones y exactos "relevés" y planos arquitectónicos. 
De gran valor son las introducciones y notas que puso nuestro nuevo consocio a dos obras ajenas: la Arquitectura Hispano-Colonial del americano Silvester Baxter, y el ya famoso Diálogo Sobre la Pintura en México, de D. José Bernardo Couto. La de Baxter, de muy lujosa presentación, fue obra meritísima para su tiempo, pero no estaba ayuna de inexactitudes y casi no tocaba los monumentos del siglo xvr, los más interesantes sin duda alguna de cuantos se han erigido en México; de manera que, al ser traducida para publicarse en español, se comprendió que era indispensable dotarla de aclaraciones $y$ adiciones, tarea que se encomendó al señor Toussaint, quien elaboró para ella una excelente introducción, amén de las correcciones que le hizo en múltiples y atinadas notas. $\mathrm{La}$ introducción es de especial valor porque, además de una buena crítica del libro, proporciona una pormenorizada reseña de cuantas obras se han escrito sobre nuestra arquitectura colonial. En cuanto al Diálogo de Couto, cuyo valor no ha decrecido con el transcurso del tiempo, fue puesto al día por Toussaint en la preciosa edición que de tal coloquio publicó el Centro de Cultura Económica.

Libro que arroja mucha luz sobre un aspecto artístico, que hasta hace poco habia pasado casi inadvertido, es su Arte Mudéjar en América, que abarca no solamente nuestro país, sino la América del Sur y aquella porción de los Estados Unidos que en un tiempo fue nuestra.

Dos obras recientes del señor Toussaint son La Conquista de Pánuco, editada por El Colegio Nacional, del que es conspicuo miembro, y el ensayo que se publicó en Sevilla con el título de Criterio Artístico de Hernán Cortés. La primera es una concienzuda, seria y documentada historia, y el segundo es un escrito importante y novedoso, que nos da a conocer el interés que tuvo y hasta el influjo que ejerció el Conquistador en varios aspectos artísticos de la naciente colonia; pero la novísima producción de su incansable pluma es la Historia del Arte Colonial, que está en puerta, y que seguramente pondrá todavía más alto el nombre del actual Director del Instituto de Investigaciones Estéticas de la Universidad Nacional Autónoma de México.

Con otros historiadores y sociólogos, colaboró Toussaint en obras de gran importancia, como la de los Planos de la Ciudad de México, Siglos XVI y XVII, y la de México y la Cultura, a la cual contribuyó con sendos artículos sobre el Arte en la Nueva España y el Arte Popular de México.

Pero el monumento que ha estudiado con más amor y que conoce más a fondo don Manuel Toussaint, es nuestra Catedral Metropolitana, 
el más insigne edificio de toda la América. Cuando en el año de 1916 se tomó el buen acuerdo de publicar en México pequeñas monografías, similares a las de la colección El Arte en España, que tan grande éxito alcanzaron en ambos mundos, el primer número, dedicado a la Catedral $y$ al Sagrario, apareció con una breve pero enjundiosa introducción de nuestro autor, estudio que más tarde amplió en el segundo tomo de la ya mencionada serie Iglesias de México, dedicado exclusivamente al templo máximo. $\mathrm{Y}$ todavía más: con mayores datos, nuevos documentos $\mathrm{y}$ elementos gráficos de primer orden, ha escrito el señor Toussaint la monumental obra La Catedral de México, que en estos días ha hecho su aparición, editada por la Comisión Diocesana de Orden y Decoro, y cuya lujosa presentación e inmejorable texto harán época en los anales bibliográficos de nuestra nación.

$\mathrm{Y}$ ahora, al tomar posesión de su sitial en esta Academia, don Manuel Toussaint y Ritter acaba de deleitarnos con un original y bien documentado estudio acerca del Arte Flamenco en la Nueva España. Fresca está en vuestra memoria la amena disertación que acabáis de escuchar, y que pone de manifiesto la deuda artística y social que la Nueva España contrajo con la antigua Flandes. Muy merecido es el elogio que tributa Toussaint a aquel benemérito varón que se llamó Fray Pedro de Gante, propulsor del arte en los primeros tiempos de la colonia, e interesante la noticia que nos da, de que entre los flamencos que acá vinieron, hubo "pintores, escultores, lapidarios y grabadores". Menciona en primer lugar a Juan Gerson, autor de los frescos de Epazoyucan y de los óleos de Tecamachalco, y al ínclito Simón Pereyns, cuya cuantiosa producción pictórica quedó esparcida por diversos ámbitos del país. En su estudio cortesiano Toussaint sospecha, con fundamento, que entre los retratos que Pereyns gustaba de pintar, figuró el del propio Conquistador, hoy desaparecido, pero copia de cuya copia es quizás uno de los que se conservan en el Hospital de. Jesús. Afortunadamente, dos obras maestras de Perinez, como se le llamó en México, perduran todavia en nuestra Catedral: el San Cristóbal y el cuadro llamado de la Virgen del Perdón, por hallarse en el retablo del altar de ese nombre. Esta hermosísima pintura se atribuyó en un tiempo a otro pintor, Francisco de Zumaya, pero a últimas fechas, al hallarse en ella la firma de Simón Pereyns, se confirmó la opinión de muchos, inclusive la muy humilde mía, de que era obra del flamenco. Todos vosotros conocéis la tradición de que Simón Pereyns, para cumplir una sentencia del Tribunal de la Inquisición, tuvo que pintar la imagen de Nuestra Señora en la puerta de su calabozo; y 
se ha tenido por cierto que aquélla era la de la Virgen del Perdón. El cuadro está pintado, efectivamente, en tela restirada sobre una puerta de madera, pero ésta no puede haber sido la puerta de un calabozo, ya que su tamaño corresponde más bien al zaguán de una casa que a la entrada de una estrecha prisión. Además, la tela está extendida sobre la parte exterior de la puerta y no sobre la interior, como hubiera sido (forzoso en) el caso, si se hubiera pintado el cuadro dentro de su calabozo.

En cuanto a Diego de Borgraf, recuerdo yo un Cristo yacente, en una colección particular, que a mi parecer, presenta las características del segundo estilo que señala Manuel Toussaint en la obra de aquel pintor barroco del siglo Xvir.

Flamenco fué también, puesto que nació en Amberes, el grabador en lámina Samuel Van der Straet, en México Stradanus, autor de los retratos de Diego de Cisneros y de Arias de Villalobos, del escudo del virrey Montesclaros y del peregrino plano de México, a que alude Toussaint; pero nuestro colega olvida mencionar la obra más importante del grabador flamenco: la Imagen Guadalupana, que ejecutó por los años de 1620 , y que hasta hoy constituye la estampa más antigua que se conoce de la Virgen del Tepeyac.

\section{Post scriptum.}

Fueron escritas las antecedentes líneas para la contestación, que me cupo en suerte pronunciar, al discurso de recepción de Manuel Toussaint en la Academia Mexicana de la Historia Correspondiente de la Real de Madrid, efectuada el 10 de febrero de 1949.

Naturalmente, no fué necesario, en aquella ocasiớn, mencionar otras importantes publicaciones suyas, como la del Proceso de Simón Pereyns, en 1938 y La influencia de Francia en el arte colonial de México, en 1944.

Como miembro de El Colegio Nacional publicó, en 1950 un estudio sobre la Catedral de Puebla, el cual, cuatro años después, incorporó en su magistral historia de La Catedral y las iglesias de Puebla, eruditísimo y bien ilustrado volumen, a pesar de su reducido formato; y tenía preparada para la imprenta la segunda serie de sus Paseos Coloniales, en la que iban a figurar capítulos sobre Huaquechula, Tenancingo, Oaxtepec, Tepalcingo, Zinacantepec y otros de igual importancia, cuando su muerte vino a impedir que nos deleitáramos con tan atrayentes estudios.

Pero, indudablemente, las dos obras más importantes del doctor Toussaint fueron la monumental Catedral de México a que me referí en mi 
discurso, y el magnífico libro Arte Colonial en México, que entonces todavía no salía de las prensas universitarias, pero que poco después apareció como segundo volumen de los tres, que forman la magna historia del arte en México, desde los tiempos antiguos hasta los modernos, escritos, respectivamente, por Salvador Toscano, el propio Toussaint y Justino Fernández. En esta obra suya, estudia don Manuel Toussaint, con profusión de datos históricos, conocimientos profundos de la materia y atinado criterio, todas las manifestaciones artísticas que ilustraron nuestro país durante las tres centurias de la dominación española, de tal manera que este volumen, magnífico por su contenido así como por su presentación, constituye, creo yo, la historia definitiva de $\tan$ interesante tema, y viene a ser, quizás, la obra cumbre del doctor don Manuel Toussaint y Ritter. 